\title{
BMJ Open Teaching the relationship between health and climate change: a systematic scoping review protocol
}

\author{
Tasnime Osama, ${ }^{1}$ David Brindley, ${ }^{2}$ Azeem Majeed, ${ }^{3}$ Kris A. Murray, ${ }^{4}$ Hiral Shah, ${ }^{4}$ \\ Mel Toumazos, ${ }^{1}$ Michelle Van Velthoven, ${ }^{1,2}$ Josip Car, ${ }^{1}$ Glenn Wells, ${ }^{5}$ \\ Edward Meinert ${ }^{1,2}$
}

To cite: Osama T, Brindley D, Majeed A, et al. Teaching the relationship between health and climate change: a systematic scoping review protocol. BMJ Open 2018;8:e020330. doi:10.1136/ bmjopen-2017-020330

- Prepublication history and additional material for this paper are available online. To view these files, please visit the journal online (http://dx.doi. org/10.1136/bmjopen-2017020330).

\section{AM, KA.M, MVV and GW contributed equally.}

Received 30 0ctober 2017 Revised 9 March 2018 Accepted 20 March 2018

\section{Check for updates}

${ }^{1}$ Global eHealth Unit,

Department of Primary Care and Public Health, School of Public

Health, Imperial College London, London, UK

${ }^{2}$ Department of Paediatrics, University of Oxford, Oxford, UK ${ }^{3}$ Department of Primary Care and Public Health, School of Public Health, Imperial College London, London, UK

${ }^{4}$ Faculty of Natural Sciences,

The Grantham Institute for Climate Change, Imperial College London, London, UK

${ }^{5}$ Oxford Academic Health

Science Centre, Oxford, UK

\section{Correspondence to}

Edward Meinert;

e.meinert14@imperial.ac.uk; edward.meinert@paediatrics. ox.ac.uk

\section{ABSTRACT}

Introduction The observed and projected impacts of climate change on human health are significant. While climate change has gathered global momentum and is taught frequently, the extent to which the relationships between climate change and health are taught remains uncertain. Education provides an opportunity to create public engagement on these issues, but the extent to which historical implementation of climate health education could be leveraged is not well understood. To address this gap, we propose to conduct a scoping review of all forms of teaching that have been used to illustrate the health effects of climate change between 2005 and 2017, coinciding with a turning point in the public health and climate change agendas following the 2005 Group of $7 / 8$ (G7/8) Summit.

Methods and analysis Using Arksey/0'Malley's and Levac's methodological framework, MEDLINE/PubMed, Embase, Scopus, Education Resource Information Centre, Web of Science, Global Health, Health Management Information Consortium, Georef, Ebsco and PROSPERO will be systematically searched. Predetermined inclusion and exclusion criteria will be applied by two independent reviewers to determine study eligibility. Studies published in English and after 2005 only will be examined. Following selection of studies, data will be extracted and analysed. Ethics and dissemination No ethical approval is required as exclusively secondary data will be used. Our findings will be communicated to the European Institute of Innovation \& Technology Health-Knowledge and Innovation Communities to assist in the development of a FutureLearn Massive Open Online Course on the health effects of climate change.

\section{BACKGROUND}

As a consequence of human activities affecting the climate, extreme weather events, warming trends and reductions in Arctic sea ice are predicted to continue over the coming decades causing irreversible consequences. ${ }^{12}$ Climate change causes significant detrimental direct ${ }^{\mathrm{i}}$

\footnotetext{
${ }^{\mathrm{i}}$ Direct effects: Effects resulting from high temperatures, low temperatures, floods, droughts. An increase in direct effects such as injuries and fatalities are observed following extreme weather events, including heat waves.
}

\section{Strengths and limitations of this study}

- A strength of this study is that it will apply a broad review of multidisciplinary databases covering medicine, health, education and the environment, providing a comprehensive assessment of published literature on courses designed on these subjects.

- A limitation of this study is that only peer-reviewed literature in English will be included, which will limit the scope of this review to articles published in English speaking countries or to those who published in English.

- A limitation of this study is that identified publications will not be subject to quality appraisal.

and indirect ${ }^{\mathrm{ii}}$ effects on human life, highlighting the importance of improving knowledge of its impact while acquiring essential skills. ${ }^{3}$ Modifiable environmental factors are responsible for $23 \%$ of worldwide mortality and $26 \%$ of deaths attributed to children under the age of 5 years, according to the WHO. ${ }^{4}$ As a rapid expansion in the knowledge pertaining to health behaviours has been gained over the last two decades, ${ }^{5}$ a dynamic exchange between learners and educators has the potential to improve environmental outcomes as well as individual and population-based health outcomes. Digital technology and education, in the form of social media, Massive Open Online Courses (MOOCs) and other forms of digital dissemination form an opportunity to leverage broad reach and impact of sharing information to the public. Expertise in how to use the latest evidence on the impact of health and climate change to inform how to effectively engage the public via digital platforms requires

\footnotetext{
ii Indirect effects: These include infectious diseases, issues pertaining to food (malnutrition) and water security. Long-term effects include population displacement, geopolitical instability, conflict and mental health consequences.
} 
specialist knowledge due to the rapidly changing nature of this medium.

Through the acquisition of knowledge and skills, education represents a key asset to combat climate change. ${ }^{6}$ According to the UNESCO, successful mitigation and adaptation may be achieved through scientific teaching and learning. ${ }^{7}$ The Lancet advocates that tackling climate change could be the biggest global health opportunity of the 21 st century; ${ }^{8}$ through the application of the Lancet Health and Climate Change Commission's multidisciplinary recommendations pertaining to education, research, collaborative actions and political commitment, seizing a global engagement opportunity through public resonance will be feasible. ${ }^{8}$ Education will play a pivotal role in the achievement of the Paris Agreement and the Sustainable Development Goal (SDG) 13 which strives to 'take urgent action to tackle climate change and its impacts'. ${ }^{9}$ Following the use of educational platforms and other means to achieve SDG 13, it is predicted that the accomplishment of other climate-related SDGs such as SDG 2 and SDG 6 which strive to 'End hunger, achieve food security and improved nutrition and promote sustainable agriculture ${ }^{, 9}$ and 'Ensure access to water and sanitation for all ${ }^{9}$ respectively will be facilitated. For example, epigenetics has demonstrated that environmental conditions can lead to modifications in the DNA of individuals adapting to changing climates; ${ }^{10}$ instruction and training can be an enabler to assist in such transitions to anticipated climates. Education creates a platform for learners to make informed decisions and build communities of practice centred on these issues, thereby strengthening, in the long run, resilience to climate change. Such democratisation of science and enhancement of societal relations may be achieved through engagement of the public in debate on issues and governmental decision-making. ${ }^{11}$

While there are many benefits to be derived from the use of climate-themed education, explaining the risks and ambiguities surrounding climate change to lay citizens remains a challenge for scientists. ${ }^{12}$ In addition to educators and institutions finding it challenging to teach, ${ }^{12}{ }^{13}$ learners find the underlying science associated with climate change difficult to understand. ${ }^{14}$ While guidelines have been developed for climate change communication, further evidence is required to understand effectiveness. ${ }^{12}$ As a way to address this engagement gap, digital learning has been shown to be more efficient than traditional learning approaches in promoting achievement and motivation in learners. ${ }^{15}$ Challenges in communicating the public health implications of climate change may, therefore, be addressed through the application of digital learning in the climate change and health education agenda.

Minimal attention has been given to the public health implications of climate change before $2005 .{ }^{16}$ In fact, during the G7/8 Summit in 2005, the need for the international community to respond to climate change was addressed. ${ }^{17}$ A renewed commitment to climate change was illustrated through the encouragement of global cooperation and responsibility. ${ }^{16}{ }^{17}$ Due to the growing interest of the international community in climate change and health, it is expected that halting humanmade harm is achievable through implementation of successful educational platforms. Despite the detrimental health effects of climate change, the extent to which they are actively taught and communicated to the public remains unclear. As there is limited understanding of the evidence of the teaching forms applied in climate change and health, the proposed review will address this gap, enabling the opportunity to apply them in using digital technology to encourage sustainable action.

\section{AIM AND OBJECTIVES}

To search the literature to identify educational approaches that have been applied to raise awareness and increase knowledge about climate change and health between 2005 and 2017. This will enable understanding of the key aspects of climate change and health education, to map strengths, weaknesses, gaps and observations in their implementation approach.

Objectives of this review are to:

1. Provide a comprehensive overview of any study on any educational approach used to enhance knowledge of the public on the direct and/or indirect health effects of climate change.

2. Disseminate review findings on the published literature about education on the health effects of climate change.

3. Develop recommendations for future climate change and health teaching, research and policy.

4. Develop propositions facilitating collaboration between learners, educators and various other stakeholders including academia and industry.

5. Provide a composite overview of evaluation of existing teaching methods and the associated strengths and weaknesses applied to climate change and health education.

6. Identify how the needs of the public and educators may be aligned, thereby enhancing knowledge on climate change and health.

7. Identify how teaching methods could be applied within a digital context to strengthen engagement and sustainable action by learners.

8. Assist the European Institute of Innovation \& Technology (EIT) Health and its education partners in the development of a FutureLearn MOOC on climate change and health by applying and disseminating review findings.

\section{METHODS}

Systematic scoping reviews aim to rapidly synthesise evidence on crucial concepts associated with broad research topics in addition to identifying the central sources and forms of evidence available. Despite methodological frameworks developed by Arksey and O'Malley ${ }^{18}$ 
and Levac et al, ${ }^{19}$ methods employed in the conduction of scoping reviews remain flexible to enable clarification of concepts and research questions following familiarisation with the literature. ${ }^{20}$ Systematic scoping reviews are beneficial in areas with emerging evidence, where evidence paucity prevents execution of systematic reviews. ${ }^{19}$ Also, by incorporating different study design, scoping reviews allow researchers to answer questions outside intervention effectiveness. ${ }^{19}$ The rapid changes in the use of digital technology in learning, combined with recent advancements in the application of climate change and health in education, correlate to this methodological choice. The flexibility of this review method will allow the authors to broadly explore the literature on the learning methods used to educate learners on the relationship between climate change and health between 2005 and 2017, while structuring findings in a repeatable manner.

The review will combine knowledge resulting from different study designs in peer-reviewed literature. Although quality assessment is not always conducted in scoping reviews, ${ }^{19}$ the methodology applied to synthesise knowledge is systematic, thereby accessible for critical analysis. Additionally, as the intent of the review is to survey learning provided, therefore quality assessment is not applicable as we are not reviewing the quality of learning in course design. The authors intend to complete the review in February 2018.

\section{Protocol design}

The PRISMA-P 2015 Checklist that was used to develop the protocol may be found in online supplementary appendix 1 . The review will be guided by the methodological approach delineated by Arksey and O'Malley and Levac et al. ${ }^{1819}$ The framework consists of the following six stages: (1) identifying the research question, (2) identifying relevant studies, (3) selection of studies, (4) charting the data, (5) collating, summarising and reporting results and (6) consultation with relevant stakeholders, thereby enabling knowledge translation. A flowchart of the six stages may be found in online supplementary appendix 2 .

Stage I: identifying the research question

Following preliminary research on climate change and health, it became apparent that evidence on the education approach concerning the relationship of climate change and health was insufficient for understanding best practice in course development, thus illustrating an evidence gap. Considering this deficiency, the review's research question in table 1 was developed.

Stage II: identifying relevant studies

\section{Search strategy}

The following electronic databases will be systematically searched: MEDLINE/PubMed, Embase, Scopus, Education Resource Information Centre, Web of Science, Global Health, Health Management Information Consortium, Georef, Ebsco and PROSPERO. Following the development of MeSH terms, subject headings and keywords used to index articles, the search strategy will be reviewed by an Imperial College medical librarian. Search terms will include MeSH and keywords related to (1) teaching, (2) learning, (3) education, (4) climate change and (5) health. Publication status, publication date and language will be subjected to limits. Hence, searches will be restricted to papers published in English between 2005 and 2017. As minimal attention was attributed to the public health implications of climate change before $2005,{ }^{16}$ papers published after 2005 only will be considered. Following the MEDLINE/ PubMed search, the search strategy will be converted and applied to the remaining databases. Details pertaining to the review's searching strategy for MEDLINE/PubMed, Embase and Scopus may be found in online supplementary appendices 3-5. Additional search strategies may be requested at a later stage (once completed) from the review's first author. Results of the database searches will be subsequently imported to EndNote, a bibliographic software. Bibliographic citations of included studies will be searched to identify any additional relevant studies.

\section{Stage III: study selection and eligibility criteria}

The EndNote software will be used to remove duplicates. Table 2 outlines the study's inclusion criteria. Based on the review's predetermined inclusion and exclusion criteria, titles and abstracts of papers will then be independently screened by two reviewers, to ensure no bias occurs. ${ }^{19}$ Ineligible papers will be eliminated. Titles and abstracts that appear to meet the review's eligibility criteria will be subjected to full-text reading. A third reviewer will assist in the selection process if the two primary reviewers cannot reach a consensus on

\section{Table 1 Review research question}

\section{Research questions}

What has been the scope of teaching and instruction that has been developed to educate learners on the relationship between health and climate change between 2005 and 2017? How can this scope be applied in a digital context to enable sustained engagement between learners and the development of sustainable communities of practice on climate change? Consideration: Which health effects will the review cover?

- Direct health effects such as heat strokes and extreme weather-related mortality.

- Indirect health effects such as infectious diseases and malnutrition.
- Conventional (defined as not using digital technology as a primary means of learner participation) learning approaches. Digital learning approaches. 
Table 2 Review inclusion criteria

\begin{tabular}{|c|c|}
\hline \multicolumn{2}{|c|}{ Inclusion criteria } \\
\hline Population & $\begin{array}{l}\text { Learners of any profession, status and } \\
\text { background. }\end{array}$ \\
\hline Intervention & $\begin{array}{l}\text { Any educational/teaching form used to } \\
\text { enhance knowledge of the public on the } \\
\text { health effects of climate change. }\end{array}$ \\
\hline Comparator & $\begin{array}{l}\text { Studies with a comparator such as } \\
\text { education provided on the effects of climate } \\
\text { change on another learning topic (eg, } \\
\text { gender inequalities). } \\
\text { Identification of studies using non-digital } \\
\text { learning approaches in contrast to those } \\
\text { using digital approaches. } \\
\text { Studies without a comparator. }\end{array}$ \\
\hline Outcomes & $\begin{array}{l}\text { The primary outcome is to determine the } \\
\text { extent to which the relationship between } \\
\text { climate change and health are taught. } \\
\text { The secondary outcome consists of } \\
\text { understanding the factors which positively } \\
\text { improve teaching the relationship between } \\
\text { public health and climate change; improved } \\
\text { awareness and environmental behaviour } \\
\text { change resulting in a reduction of climate } \\
\text { change impacts will have positive public } \\
\text { health benefits. }\end{array}$ \\
\hline Study type & $\begin{array}{l}\text { Any study type (study type will not be } \\
\text { subjected to any restrictions). } \\
\text { Publications between } 2005 \text { and } 2017 \text {. } \\
\text { English publications. }\end{array}$ \\
\hline
\end{tabular}

study eligibility. A PRISMA flow diagram will be used to demonstrate the review's selection process and exclusion reasons, demonstrating replicability and transparency. This stage will represent an iterative process, incorporating search of the literature, refinement of search strategies and selection of articles. ${ }^{19}$

\section{Exclusion criteria}

- Papers published before 2005.

- Non-English publications.

\section{Stage IV: charting the data}

Predetermined data charting forms will be used to retrieve data from included papers. Extracted data will include author, study type, publication date, study characteristics (location, educational setting (eg, medicine or life sciences department in universities), use of control), learner characteristics (profession, number of participants, age), educator characteristics (number, age, profession), intervention details (educational method, educational content, length/duration, outcome measures, outcome results, financial support). The review will map the educational approaches used between 2005 and 2017 in climate change and health literature. To assure that all relevant data are collected adequately, the forms used for data extraction will be reviewed by the research team prior to implementation. Data extraction will be conducted independently by two reviewers before comparing forms. Differences will be discussed (if necessary with a third reviewer) before producing a single form containing the required data.

\section{Stage V: collating, summarising and reporting results}

Systematic scoping reviews provide an overview by answering broad questions. ${ }^{20}$ Following data extraction, results will be presented: (1) numerically-synopsis of the amount and type of included studies and (ii) narratively—a synthesis of all included studies. The authors will discuss implications of the findings on future research, practice and policy. ${ }^{19}$ To provide a holistic analysis, the structure of the intervention of interest (all teaching forms used to teach learners the relationship between climate change and health) will be captured by recording pedagogy, course content and learning outcomes. This will consist of data including, but not limited to educational method, educational content, length/duration, outcome measures, outcome results and financial support. We believe that this approach will allow us to determine the educational experience of learners and educators as the needs of learners, learner-educator interactions, learner-learner interactions, contributions of the department and use of information to nudge behaviours and improve decision-making skills will be considered. Details of Stage V remain in progress and will be finalised in November 2017. However, they may be reiterated or updated if reviewers see fit.

\section{Stage VI: consultation}

Public health professors and experts from Imperial College's Department of Primary Care \& Public Health, Imperial College's and the London School of Economics' Grantham Institute (a renowned authority on climate change and the environment), Oxford University and Université Grenoble Alpes, will be consulted, thus providing valuable insights beyond what has been captured through literature search.

\section{Patient and public involvement}

A workshop in July 2018 at the European Scientific Institute defined public priorities and experiences. At this session, members of the public identified and prioritised areas of interest which were used to construct the parameters of this search.

\section{ETHICS AND DISSEMINATION}

Following successful completion of the review, educational approaches applied over the last 12 years in the teaching of the health effects of climate change will be determined. The study findings will enable the understanding of improved and effective educational approaches, materials, tools and content on climate change and health that may enhance civic engagement through empowerment of the public with the required 
skills and tools to overcome this global challenge. In addition to developing recommendations that align the needs of learners and educators, approaches for vulnerable populations, which remain to be targeted, will be considered and disseminated. The results will be used by the EIT Health-Knowledge and Innovation Communities to assist in the development of a forthcoming MOOC on the health effects of climate change.

As data collection for the scoping review methodology uses exclusively secondary data, no ethical approval is required. Review findings will be disseminated through educational materials and publication in a peer-reviewed journal. Aspiring to tackle the greatest global health challenge of our time, ${ }^{8}$ we aim to use the knowledge gained from the review to develop for citizens, industry and universities key concepts for further development of learning infrastructure that will enable positive global change.

Acknowledgements We thank the Imperial College medical librarian for advising us on methods required to conduct a systematic search strategy. We thank the students at the EIT Health IBD4Health Summer School for participation in the research questions scoping workshop to identify search priorities.

Contributors T0 wrote the draft report, incorporated all feedback received from authors, re-drafted and finalised the manuscript and conducted preliminary research and database searches. AM revised the first draft. DB revised the second draft. JC revised the second draft. KM revised the second draft and provided valuable feedback based on his climate change expertise. HS revised the first and second draft and provided valuable feedback based on his climate change expertise. MT revised the second draft and reviewed the BMJ Open guidelines. MVV revised the first and second draft. GW revised the second draft. EM conceived the study aims and objectives, contributed to the initial draft and methodological review, revised both drafts, responded to external peer review feedback and provided oversight. The Imperial College medical librarian advised on the protocol's searching strategy. The final manuscript was approved by all authors. The guarantor is $\mathrm{EM}$.

Funding This work was supported by EIT Health, grant number 17699, the Sir David Cooksey Fellowship in Healthcare Translation, the SENS Research Foundation and the Oxford Academic Health Science Centre.

Competing interests None declared.

Patient consent Not required.

Provenance and peer review Not commissioned; externally peer reviewed.

Open Access This is an Open Access article distributed in accordance with the Creative Commons Attribution Non Commercial (CC BY-NC 4.0) license, which permits others to distribute, remix, adapt, build upon this work non-commercially, and license their derivative works on different terms, provided the original work is properly cited and the use is non-commercial. See: http://creativecommons.org/ licenses/by-nc/4.0/

(c) Article author(s) (or their employer(s) unless otherwise stated in the text of the article) 2018. All rights reserved. No commercial use is permitted unless otherwise expressly granted.

\section{REFERENCES}

1. United Nations Development Programme. 13 climate action. http:// www.undp.org/content/undp/en/home/sustainable-developmentgoals/goal-13-climate-action.html (accessed 9 Aug 2017).

2. Wuebbles D, Fahey D, Hibbard K. U.S. global change research program Climate Science Special Report (CSSR). $2017 \mathrm{https} / / /$ assets.documentcloud.org/documents/3920195/Final-Draft-of-theClimate-Science-Special-Report.pdf (accessed 9 Aug 2017).

3. National Research Council. Climate change education: goals, audiences, and strategies: a workshop summary. Washington, DC: The National Academies Press, 2011. https://doi.org/10.17226/ 13224. (accessed 8 Aug 2017).

4. World Health Organisation. Preventing disease through healthy environments: a global assessment of the burden of disease from environmental risks. http://www.who.int/quantifying_ehimpacts/ publications/preventing-disease/en/ (accessed 28 Jul 2017).

5. Glanz K, Rimer BK, Viswanath K, et al. Health behavior and health education: theory, research, and practice. San Francisco: John Wiley \& Sons, 2008.

6. Anderson A. Climate change education for mitigation and adaptation. J Educ Sustain Dev 2012;6:191-206.

7. United Nations Educational, Scientific and Cultural Organization. The UNESCO strategy for action on climate change. $2009 \mathrm{http} / / /$ unesdoc.unesco.org/images/0016/001627/162715e.pdf (accessed 8 Aug 2017).

8. Wang $\mathrm{H}$, Horton R. Tackling climate change: the greatest opportunity for global health. Lancet 2015;386:1798-9.

9. United Nations. Sustainable development goals. 17 goals to transform our word. http://www.un.org/sustainabledevelopment/ sustainable-development-goals/ (accessed 8 Aug 2017).

10. Dodd RS, Douhovnikoff V. Adjusting to global change through clonal growth and epigenetic variation. Front Ecol Evol 2016;4 https://doi. org/10.3389/fevo.2016.00086

11. Swim J, Clayton S, Doherty T, et al. Psychology and global climate change: addressing a multi-faceted phenomenon and set of challenges. Washington, DC: American Psychological Association, 2009. http://www.apa.org/science/about/publications/climatechange.pdf. (accessed 14 Sep 2017).

12. Pidgeon N, Fischhoff B. The role of social and decision sciences in communicating uncertain climate risks. Nat Clim Chang 2011;1:35-41.

13. National Research Council. Climate change education in formal settings, K-14: a workshop summary. Washington, DC: The National Academies Press, 2012. https://doi.org/10.17226/13435. (accessed 8 Aug 2017).

14. Dove J. Student teacher understanding of the greenhouse effect, ozone layer depletion and acid rain. Environmental Education Research 1996;2:89-100.

15. Smeda N, Dakich E, Sharda N. The effectiveness of digital storytelling in the classrooms: a comprehensive study. Smart Learning Environments 2014;1.

16. Kirton J, Kokotsis E. G7 governance of climate change. http://www. g8.utoronto.ca/conferences/2017/Kirton_Kokotsis_Warren.pdf (accessed 9 Aug 2017).

17. Schmidt J. Since 2005 the $G 7$ has recognized threat of climate change: NRDC, 2017. https://www.nrdc.org/experts/2005-g7-hasrecognized-threat-climate-change (accessed 9 Aug 2017).

18. Arksey H, O'Malley L. Scoping studies: towards a methodological framework. Int J Soc Res Methodol 2007;9:19-32.

19. Levac D, Colquhoun H, O'Brien KK. Scoping studies: advancing the methodology. Implement Sci 2010;5:69.

20. Daudt HM, van Mossel C, Scott SJ. Enhancing the scoping study methodology: a large, inter-professional team's experience with Arksey and O'Malley's framework. BMC Med Res Methodol 2013;13:48. 